\title{
Alternating Hemiplegia of Childhood: Pharmacological treatment of 30 Italian patients
}

\author{
Livia Pisciotta $^{\mathrm{a}, 1}$, Marcella Gherzi ${ }^{\mathrm{a}, 1}$, Michela Stagnaro ${ }^{\mathrm{a}}$, Maria Grazia Calevo ${ }^{\mathrm{b}}$, \\ Melania Giannotta ${ }^{\mathrm{c}}$, Maria Rosaria Vavassori ${ }^{\mathrm{d}}$, Edvige Veneselli ${ }^{\mathrm{a}}$, \\ I.B.AHC Consortium ${ }^{2}$, Elisa De Grandis ${ }^{\text {a,* }}$ \\ ${ }^{\text {a } C h i l d ~ N e u r o p s y c h i a t r y ~ U n i t, ~ I s t i t u t o ~ G i a n n i n a ~ G a s l i n i, ~ D e p a r t m e n t ~ o f ~ N e u r o s c i e n c e s, ~ R e h a b i l i t a t i o n, ~ O p h t h a l m o l o g y, ~ G e n e t i c s ~ a n d ~ M a t e r n a l ~}$ \\ and Children's Sciences, University of Genoa, Genoa, Italy \\ ${ }^{\mathrm{b}}$ Epidemiology, Biostatistics and Committees Unit, Istituto Giannina Gaslini, Genoa, Italy \\ ${ }^{\mathrm{c}}$ Child Neurology Unit, Maggiore Hospital, Bologna, Italy \\ ${ }^{\mathrm{d}}$ IAHCRC International Consortium, Lyon, France
}

Received 20 November 2016; received in revised form 22 January 2017; accepted 2 February 2017

\begin{abstract}
Background: Alternating Hemiplegia of Childhood (AHC) is a severe disorder. Several drugs have been administered as prophylaxis for paroxysmal attacks, however, no therapy is completely effective.

Methods: Our aim is to review the pharmacological data related to the prophylactic and acute treatment of a cohort of 30 patients (16 M, $14 \mathrm{~F}$, age range 5-42 years) and to correlate them with the clinical and genetic data collected through the Italian Biobank and Clinical Registry for AHC.

Results: Flunarizine was the most commonly used long-term treatment in the cohort; it reduced duration and frequency of attacks in $50 \%$ of patients and decreased intensity in $32.1 \%$. In younger patients, flunarizine seemed significantly more effective in reducing intensity. We found no correlation between the effectiveness of flunarizine and genotype, or between developmental outcome and duration of treatment. In particular, 3 of our patients affected by E $815 \mathrm{~K}$ mutation presented rapid neurological deterioration despite ongoing treatment. Among the other administered prophylactic therapies, few proved to be effective (benzodiazepines, niaprazine, acetazolamide, melatonin, olanzapine, ketogenic diet). No clear rationale exists regarding their use, but these therapies may work by reducing the triggering factors.

Conclusions: The presented data are retrospective, but they are aimed at filling a gap given the rarity of the disease and the lack of randomized and controlled studies. Besides their usefulness in clarifying the pathophysiology of the disease, prospective studies involving larger cohorts of $A T P 1 A 3$ mutated AHC patients are needed to provide a rationale for testing other molecules.
\end{abstract} (C) 2017 The Japanese Society of Child Neurology. Published by Elsevier B.V. All rights reserved.

Keywords: Alternating Hemiplegia; ATP1 A3; Flunarizine; Phenotype; Genotype; Treatment

\footnotetext{
* Corresponding author at: Department of Neuroscience, Rehabilitation, Ophthalmology, Genetics and Maternal and Child Health, Child Neuropsychiatry Unit, Istituto Giannina Gaslini, University of Genoa, Largo Gaslini 5, 16147 Genoa, Italy. Fax: +39 01056363463.

E-mail address: elisadegrandis@gaslini.org (E. De Grandis).

1 These authors contributed equally to the work.

2 I.B.AHC Italian Consortium: Maria Teresa Bassi, Claudio Zucca - Scientific Institute IRCCS E. Medea, Bosisio Parini (LC); Elisa De Grandis, Michela Stagnaro, Edvige Veneselli - Istituto G. Gaslini, University of Genoa, Genoa; Filippo Franchini - A.I.S.EA Onlus, Milan; Melania Giannotta, Giuseppe Gobbi - IRCCS Istituto delle Scienze Neurologiche di Bologna, Bologna; Tiziana Granata, Nardo Nardocci, Francesca Ragona - IRCCS Foundation Neurological Institute C. Besta, Milan; Fiorella Gurrieri, Giovanni Neri, Francesco Danilo Tiziano - Istituto di Medicina Genomica Università Cattolica del S. Cuore, Rome; Federico Vigevano - Bambino Gesù Children's Hospital, IRCCS, Rome.
} 


\section{Introduction}

Alternating Hemiplegia of Childhood (AHC) is a rare, predominantly sporadic disorder with an incidence of one affected individual in one million births (OMIM 104290,614820 ), and it is characterized by the early onset (within 18 months of age) of a combination of paroxysmal attacks and permanent neurological features.

The etiology of the syndrome was unknown until 2012, when heterozygous de novo mutations in the ATP1A3 gene that codes for the $\alpha 3$ isoform of the $\mathrm{Na}$ $+/ \mathrm{K}+$ ATPase were detected in more than $75 \%$ of AHC patients [1].

Since phenotype variability of AHC is extensive, drug therapy is often difficult and challenging. The main objectives of drug therapy are to prevent paroxysmal attacks by means of prophylactic therapy, and to stop paroxysms by inducing sleep which often blocks a crisis. Other paroxysmal manifestations requiring treatment include epilepsy (which may be associated in approximately $50 \%$ of patients) and migraine. Several combinations of movement disorders (such as chorea, myoclonus and dystonia) with various degrees of severity, and psychiatric comorbidities vary from patient to patient and represent other targets for treatment.

Several drugs have been used since AHC was first described, mainly to control the paroxysmal attacks that represent the most disturbing symptoms. Due to the rarity of this disease, prospective, randomized and controlled studies are lacking. Currently, only flunarizine, a calcium entry blocker, has been shown to reduce the severity and/or duration of AHC attacks $[2,3]$.

The aim of this study was to review the pharmacological data regarding the prophylactic and acute treatment of an Italian cohort of patients and to correlate treatment response to clinical, demographic and genetic data.

\section{Subjects}

The clinical, demographic, genetic and pharmacological data of 30 AHC patients (16 males - 53.3\%, 14 females - 46.7\%) ranging in age from 5 to 42 years ( $20.9 \pm 10$ years) were collected from the I.B.AHC (the Italian Biobank and Clinical Registry for AHC: www. ibahc.org). Data were collected by the patient's referring paediatric neurologist and subsequently validated by the I.B.AHC data managers (MG, EDG and MS). Diagnoses were established by consensus among the members of the Scientific Committee of the Italian Patient Association (A.I.S.EA) on the basis of the 7 specific diagnostic clinical criteria [4] and by analysing video recordings during and between paroxysmal attacks. All patients (or parents acting on their behalf) gave informed consent to participate in the study and each patient underwent molecular analysis of the $A T P 1 A 3$ gene.

\section{Methods}

The following data were analysed: onset of disease; age at last follow-up; gender; clinical manifestations (epilepsy, migraine, cognitive impairment, dystonia, walking disability, language impairment); genotype (presence and type of ATP1A3 mutation); frequency, severity and duration of each type of paroxysmal attack (tonic/dystonic/plegic) before and after administration of every prophylactic and/or symptomatic therapy; reported side effects.

Drugs were classified as follows: sleep-inducing treatments, benzodiazepines, anti-epileptic drugs (AEDs), drugs for spasticity and movement disorders, antimigraine, antidepressant, anti-psychotic, anti-inflammatory (including non steroidal anti inflammatory drugs), paracetamol, corticosteroids, hormonal therapies, vitamins and supplements, homeopathy and other therapies (ketogenic diet (KD), vagal stimulation, relaxation techniques). A favourable response was empirically defined as a clinically significant reduction in terms of frequency, duration or intensity of the spells according to the referring neurologist, evident and sufficient to warrant continuation of the treatment.

Treatment with flunarizine was specifically analysed. Using the I.B.AHC database, as well as the patients' charts and the interviews with family members and parents, we rated intensity, duration and frequency of the attacks before and after treatment in order to achieve data standardization. A numerical scale ranging from 1 to $10(1=$ low intensity, $10=$ high intensity $)$ was used to assess the intensity of the attacks, while duration was measured in hours, and frequency in number of episodes per week. The percentage of positive or negative modifications was calculated for each item in order to measure the effects of flunarizine, while to better define the number of patients in whom there was no or only minimum change in the frequency, intensity, and duration of paroxysmal attacks, we decided to categorize the response rate, considering a minimum cut-off of $30 \%$ as a significant decrease.

The Flunarizine Index (FI), defined as the duration of the treatment with flunarizine divided by the patient's age [2], was also calculated.

The hypothesis that the cognitive and neurological outcome of these patients might be correlated with the duration of flunarizine treatment was investigated by comparing the FI to the cognitive profile, the presence and severity of dystonia and any impairment of autonomous walking and speech.

The data in our statistical analysis were described as mean and standard deviation (SD) or median and range 
for continuous variables, and as absolute and relative frequencies for categorical variables.

The normality of variables distribution was assessed using the Kolmogorov-Smirnov test.

Non parametric analysis (Kruskal-Wallis, MannWhitney and Wilcoxon tests) for continuous variables and the Chi square or Fisher's exact test for categorical variables were used to measure differences between groups. A $p$-value less than 0.05 was considered statistically significant; all $p$-values were based on two-tailed tests. Statistical analysis was performed using SPSS for Windows (SPSS Inc., Chicago, Illinois USA).

\section{Results}

The clinical features of our series of 30 patients are shown in Table 1.

In our cohort flunarizine was used in 29/30 patients for a mean period of 12.8 years $( \pm 9.8 \mathrm{SD})$, ranging from 12 months to 28 years, median value 10 years. Data about daily dosage of flunarizine were available in $23 / 29$ patients: mean value $8.2 \mathrm{mg} /$ day $\pm 2.9 \mathrm{SD}$, median value $10 \mathrm{mg} /$ day (range $3.25-15$ ). Side effects [worsening of dystonia $(n=2)$, sedation $(n=1)$, rash $(n=1)$, gingival hypertrophy $(n=1)$, weight gain $(n=1)$ and disequilibrium $(n=1)]$ per se were mild and transient, but together with the lack of efficacy, they led to permanent or temporary discontinuation of the therapy in 13/29 patients. Four out of 13 patients $(30.8 \%)$ permanently discontinued the treatment, while $1 / 13(7.7 \%)$ temporarily discontinued flunarizine for 6-7 months due to side effects resulting from dose elevation. Eight out of 13 $(61.5 \%)$ later resumed therapy due to the worsening of symptoms after discontinuation. None of the patients discontinued flunarizine solely due to the side effects, but also because of a lack of efficacy. In our statistical analysis of the efficacy of flunarizine we considered 28/29 patients because one patient (aged 23) had been on the drug since early in life, thus making it difficult to assess the effectiveness of the treatment on attacks. In the 28 patients who were administered flunarizine, a significant improvement in terms of duration, intensity and frequency of attacks ( $p=0.02, p=0.005$ and $p=0.0001$, respectively) was observed between pre- versus post-treatment (Table 2). A greater than 30\% reduction in the duration of attacks was reported in 14/28 $(50 \%)$, and lower intensity was observed in $9 / 28$ $(32.1 \%)$. A reduction in frequency greater than $30 \%$ was reported in $14 / 28$ patients $(50 \%)$, while in five patients flunarizine was not effective on any of the parameters. Six out of 28 patients $(21.4 \%)$ had a $>30 \%$ decrease in all parameters; $2 / 28(7.1 \%)$ had a $>50 \%$ decrease in all parameters; none had a greater than $75 \%$ response in all parameters.

Comparing the age of the patients to the effectiveness of flunarizine (in terms of reduction of frequency,
Table 1

Characteristics of patients with Alternating Hemiplegia of Childhood.

\begin{tabular}{|c|c|}
\hline Characteristics of Patients & All N (\%) \\
\hline $\mathrm{N}$ & 30 \\
\hline Age at onset (months) Mean \pm SD & $2.6 \pm 3.1$ \\
\hline Median (range) & $1(0 ; 13)$ \\
\hline Age at last follow-up (years) Mean \pm SD & $20.9 \pm 10$ \\
\hline Median (range) & $20(5 ; 42)$ \\
\hline Gender $\mathrm{M} / \mathrm{F}$ & $16 / 14(53.3 / 46.7)$ \\
\hline Epilepsy, yes & $12(40)$ \\
\hline Migraine, yes & $14(46.7)$ \\
\hline \multicolumn{2}{|l|}{ Cognitive impairment } \\
\hline Absent & $1(3.33)$ \\
\hline Mild & $10(33.3)$ \\
\hline Moderate & $11(36.7)$ \\
\hline Severe & $8(26.7)$ \\
\hline \multicolumn{2}{|l|}{ Dystonia } \\
\hline Absent & $6(20)$ \\
\hline Mild & $14(46.7)$ \\
\hline Moderate & $6(20)$ \\
\hline Severe & $4(13.3)$ \\
\hline \multicolumn{2}{|l|}{ Walking } \\
\hline Autonomous & $20(66.7)$ \\
\hline Not autonomous & $4(13.3)$ \\
\hline Impossible & $6(20)$ \\
\hline \multicolumn{2}{|l|}{ Language } \\
\hline Normal & $11(36.7)$ \\
\hline Mild impairment & $5(16.7)$ \\
\hline Moderate impairment & $8(26.7)$ \\
\hline Severe impairment/averbal patient & $6(20)$ \\
\hline \multicolumn{2}{|l|}{ Genotype ( $A T P 1 A 3$ mutation) } \\
\hline $\mathrm{D} 801 \mathrm{~N}$ & $10(33.3)$ \\
\hline $\mathrm{E} 815 \mathrm{~K}$ & $7(23.3)$ \\
\hline G947R & $2(6.7)$ \\
\hline A955D & $1(3.3)$ \\
\hline $\mathrm{C} 333 \mathrm{~F}$ & $1(3.3)$ \\
\hline 919delV & $1(3.3)$ \\
\hline A338P & $1(3.3)$ \\
\hline $\mathrm{I} 274 \mathrm{~N}$ & $1(3.3)$ \\
\hline L888P & $1(3.3)$ \\
\hline M806R & $1(3.3)$ \\
\hline Negative at genetic investigations & $4(13.3)$ \\
\hline
\end{tabular}

intensity and duration of paroxysmal attacks) revealed no significant correlations except that in younger patients flunarizine was significantly more effective in reducing the intensity of attacks (percentage of reduction $15.8 \pm 8.6$ vs $24.4 \pm 8.6, p=0.01$ ).

Comparing the FI to long-term clinical outcome, no statistically significant correlations were found (absent or mild cognitive impairment $0.65 \pm 0.32$ vs moderate or severe $0.58 \pm 0.36, p=0.62$; absent or mild dystonia $0.60 \pm 0.35$ vs moderate or severe dystonia $0.62 \pm 0.36$, $p=0.98$; autonomous walking $0.64 \pm 0.33$ vs not autonomous or impossible $0.46 \pm 0.38, p=0.21$; mild or no language impairment $0.65 \pm 0.33$ vs moderate or severe language impairment $0.55 \pm 0.37, p=0.35$ ) (Table 3).

Moreover, no statistically significant correlation between the developmental outcome and flunarizine 
Table 2

Effects of Flunarizine on duration, intensity and frequency of paroxysmal attacks in Alternating Hemiplegia of Childhood.

\begin{tabular}{llll}
\hline Effect of Flunarizine & Pre-Flunarizine & Post-Flunarizine & $P$ value \\
\hline $\mathrm{N}$ & 28 & 28 & $38.8 \pm 57$ \\
Duration of attacks (hours) mean $\pm \mathrm{SD}$ & $82.6 \pm 140$ & $9(0.03 ; 240)$ \\
median (range) & $48(0.3 ; 730)$ & $6.2 \pm 2.2$ & 0.002 \\
Intensity of attacks $\left.^{*}{ }^{\prime}\right)$ mean $\pm \mathrm{SD}$ & $7.8 \pm 1.9$ & $6(1 ; 10)$ & $1.8 \pm 3$ \\
median (range) & $8(2 ; 10)$ & $0.75(0.06 ; 14)$ \\
Frequency of attacks (per week) mean $\pm \mathrm{SD}$ & $5.3 \pm 12.9$ & 0.005 \\
median (range) & $1(0.12 ; 70)$ & 0.0001 \\
\hline
\end{tabular}

* Numerical scale ranging from 1 to $10(1=$ low intensity, $10=$ high intensity).

efficacy on the duration, intensity and frequency of attacks was found (Supplemental Table).

In order to evaluate the correlation between the effectiveness of flunarizine and the genotype, we considered the two most frequent mutations (D801N, E815K) and grouped all other mutations. Then we divided the patients into four groups: patients with D801N (8 cases); patients with E815K ( 7 cases); patients with other mutations (9 cases); patients with no mutations (4 cases).

Table 3

Long-term clinical outcome - Correlations of the effect of Flunarizine in Alternating Hemiplegia of Childhood.

\begin{tabular}{|c|c|c|c|c|c|c|c|c|c|c|}
\hline Patient & $\begin{array}{l}\text { Age } \\
\text { (years) }\end{array}$ & $\begin{array}{l}\text { Genotype } \\
\text { (ATP1A3 } \\
\text { mutation) }\end{array}$ & FI & $\begin{array}{l}\text { Effect of } \\
\text { Flunarizine on } \\
\text { duration } \\
\text { of attacks }\end{array}$ & $\begin{array}{l}\text { Effect of } \\
\text { Flunarizine on } \\
\text { intensity } \\
\text { of attacks }\end{array}$ & $\begin{array}{l}\text { Effect of } \\
\text { Flunarizine on } \\
\text { frequency } \\
\text { of attacks }\end{array}$ & $\begin{array}{l}\text { Cognitive } \\
\text { impairment }\end{array}$ & Dystonia & Walking & Language \\
\hline 1 & 9 & E815K & 0.50 & 2 & 0 & 0 & 3 & 0 & 2 & 3 \\
\hline 2 & 16 & neg & 0.73 & 0 & 1 & 0 & 2 & 3 & 1 & 2 \\
\hline 3 & 13 & $\mathrm{C} 333 \mathrm{~F}$ & 0.83 & 2 & 1 & 2 & 1 & 1 & 0 & 1 \\
\hline 4 & 17 & neg & 0.04 & 2 & 2 & 2 & 2 & 2 & 0 & 2 \\
\hline 5 & 24 & D801N & 0.09 & 2 & 2 & 1 & 1 & 1 & 0 & 1 \\
\hline 6 & 23 & D801N & 0.95 & $/ /$ & $/ /$ & $/ /$ & 1 & 1 & 0 & 0 \\
\hline 7 & 9 & G947R & 0.75 & 0 & 0 & 0 & 1 & 1 & 0 & 0 \\
\hline 8 & 17 & G947R & 0.86 & 2 & 2 & 2 & 1 & 1 & 0 & 0 \\
\hline 9 & 22 & 919delV & 0.81 & 0 & 3 & 0 & 2 & 2 & 0 & 2 \\
\hline 10 & 14 & $\mathrm{I} 274 \mathrm{~N}$ & 0.77 & 0 & 0 & 0 & 1 & 1 & 0 & 0 \\
\hline 11 & 29 & D801N & 0.94 & 0 & 1 & 0 & 2 & 0 & 0 & 0 \\
\hline 12 & 37 & D801N & 0.78 & 0 & 0 & 2 & 2 & 1 & 0 & 1 \\
\hline 13 & 14 & E815K & 0.99 & 1 & 2 & 2 & 2 & 2 & 0 & 2 \\
\hline 14 & 43 & D801N & 0 & // & // & // & 2 & 0 & 0 & 0 \\
\hline 15 & 31 & neg & 0.90 & 2 & 2 & 0 & 1 & 1 & 0 & 0 \\
\hline 16 & 23 & E815K & 0.05 & 0 & 0 & 0 & 3 & 2 & 1 & 2 \\
\hline 17 & 35 & E815K & 0.70 & 2 & 2 & 0 & 3 & 3 & 2 & 3 \\
\hline 18 & 35 & E815K & 0.70 & 2 & 2 & 0 & 3 & 3 & 2 & 3 \\
\hline 19 & 6 & D801N & 0.50 & 0 & 1 & 2 & 0 & 0 & 0 & 0 \\
\hline 20 & 39 & D801N & 0.71 & 0 & 2 & 1 & 2 & 1 & 0 & 0 \\
\hline 21 & 29 & neg & 0.11 & 2 & 2 & 0 & 2 & 1 & 0 & 0 \\
\hline 22 & 15 & M806R & 0.86 & 3 & 1 & 1 & 1 & 1 & 1 & 2 \\
\hline 23 & 18 & $\mathrm{E} 815 \mathrm{~K}$ & 0.29 & 0 & 0 & 0 & 3 & 3 & 2 & 3 \\
\hline 24 & 26 & D801N & 0.92 & 0 & 2 & 0 & 1 & 0 & 0 & 0 \\
\hline 25 & 20 & $\mathrm{D} 801 \mathrm{~N}$ & 0.93 & 2 & 2 & 2 & 2 & 1 & 0 & 1 \\
\hline 26 & 13 & E815K & 0.95 & 0 & 0 & 1 & 3 & 2 & 2 & 2 \\
\hline 27 & 13 & A955D & 0.08 & 2 & 2 & 2 & 3 & 1 & 2 & 3 \\
\hline 28 & 23 & L888P & 0.91 & 0 & 0 & 2 & 3 & 2 & 1 & 3 \\
\hline 29 & 34 & D801N & 0.06 & 2 & 2 & 2 & 1 & 1 & 0 & 1 \\
\hline 30 & 9 & A338P & 0.63 & 0 & 0 & 0 & 2 & 0 & 0 & 2 \\
\hline
\end{tabular}

Genotype: neg = patient resulted negative at molecular analysis of the ATP1A3 gene;

FI (Flunarizine Index) = duration of Flunarizine treatment/patient's age;

Effect of Flunarizine on frequency/intensity/duration of attacks: $0=$ reduction $>30 \%, 1=$ reduction $<30 \%, 2=$ no effect, $3=$ worsening, $/ /$ = patient that was never administered Flunarizine or unassessable data;

Cognitive Impairment: $0=$ absent, $1=$ mild, $2=$ moderate, $3=$ severe;

Dystonia: $0=$ absent, $1=$ mild, $2=$ moderate, $3=$ severe;

Walking: $0=$ autonomous; $1=$ not autonomous, $2=$ impossible;

Language: $0=$ normal, $1=$ mild impairment, $2=$ moderate impairment, $3=$ severe impairment. 
Table 4

Effect of flunarizine on genotype in Alternating Hemiplegia of Childhood.

\begin{tabular}{|c|c|c|c|c|c|c|c|c|c|c|c|}
\hline Flunarizine effect & All $n=28$ & $\begin{array}{l}\text { Group 1 } \\
\text { D801N } \\
\text { Mutation } \\
N=8\end{array}$ & $\begin{array}{l}\text { Group } 2 \\
\text { E815K } \\
\text { Mutation } \\
N=7\end{array}$ & $\begin{array}{l}\text { Group } 3 \\
\text { Other } \\
\text { Mutation } \\
N=9\end{array}$ & $\begin{array}{l}\text { Group } 4 \\
\text { No } A T P 1 A 3 \\
\text { Mutation } \\
N=4\end{array}$ & $\begin{array}{l}p \text {-Value } \\
1 \text { vs } 2\end{array}$ & $\begin{array}{l}p \text {-Value } \\
1 \text { vs } 3\end{array}$ & $\begin{array}{l}p \text {-Value } \\
1 \text { vs } 4\end{array}$ & $\begin{array}{l}p \text {-Value } \\
2 \text { vs } 3\end{array}$ & $\begin{array}{l}p \text {-Value } \\
2 \text { vs } 4\end{array}$ & $\begin{array}{l}p \text {-Value } \\
3 \text { vs } 4\end{array}$ \\
\hline & $N(\%)$ & $N(\%)$ & $N(\%)$ & $N(\%)$ & $N(\%)$ & & & & & & \\
\hline $\begin{array}{l}\text { Frequency } \\
\text { Reduction } \\
\text { No effect }\end{array}$ & $\begin{array}{l}18(64.3) \\
10(35.7)\end{array}$ & $\begin{array}{l}4(50) \\
4(50)\end{array}$ & $\begin{array}{l}6(85.7) \\
1(14.3)\end{array}$ & $\begin{array}{l}5(55.6) \\
4(44.4)\end{array}$ & $\begin{array}{l}3(75) \\
1(25)\end{array}$ & 0.28 & 1 & 0.57 & 0.31 & 1 & 1 \\
\hline $\begin{array}{l}\text { Intensity } \\
\text { Reduction } \\
\text { No effect }\end{array}$ & $\begin{array}{l}14(50) \\
14(50)\end{array}$ & $\begin{array}{l}3(37.5) \\
5(62.5)\end{array}$ & $\begin{array}{l}4(57.1) \\
3(42.9)\end{array}$ & $\begin{array}{l}6(66.7) \\
3(33.3)\end{array}$ & $\begin{array}{l}1(25) \\
3(75)\end{array}$ & 0.62 & 0.35 & 1 & 1 & 0.54 & 0.27 \\
\hline $\begin{array}{l}\text { Duration } \\
\text { Reduction } \\
\text { No effect }\end{array}$ & $\begin{array}{l}15(53.6) \\
13(46.4)\end{array}$ & $\begin{array}{l}5(62.5) \\
3(37.5)\end{array}$ & $\begin{array}{l}4(57.1) \\
3(42.9)\end{array}$ & $\begin{array}{l}5(55.6) \\
4(44.4)\end{array}$ & $\begin{array}{l}1(25) \\
3(75)\end{array}$ & 1 & 1 & 0.54 & 1 & 0.54 & 0.56 \\
\hline
\end{tabular}

Fisher's exact test.

Statistical analysis of the effectiveness of flunarizine in terms of reducing the frequency, duration and intensity of the attacks did not yield any statistically specific or significant correlations when comparing the four groups (Table 4). The clinical data of all patients was compared among these mutation groups and statistically significant differences were observed in group 2 , in relation to other groups (Table 5). Clinical outcome was definitely better in patients with the D801N mutation (dystonia, cognitive impairment, walking and language), and in particular, as compared to patients with the E815K mutation. At the time of evaluation, none of the 7 patients with the E815K mutation had ever discontinued flunarizine; despite ongoing treatment, three of them experienced psychomotor regression. Two patients (twins, patients n. 17 and 18) became bedridden and lost the ability to speak, apparently because of status epilepticus; patient n. 26 had a behavioural regression due to ongoing severe dystonic episodes, and died a few months later of a heart attack.

In our cohort of 30 patients, $24(80 \%)$ had received AEDs during their life, often in polytherapy. The most often used AEDs in our cohort were: valproic acid $(16 / 24)$, phenobarbital $(14 / 24)$, carbamazepine $(13 / 24)$, topiramate $(10 / 24)$, clobazam $(8 / 24)$, phenytoin $(6 / 24)$, lamotrigine (3/24), ethosuximide $(2 / 24)$, vigabatrin $(1 / 24)$, felbamate $(1 / 24)$ and levetiracetam $(1 / 24)$. None of these AEDs was reported to be effective on nonepileptic paroxysmal attacks.

Some other prophylactic drugs proved to be effective: benzodiazepines (7/12), niaprazine (4/7), acetazolamide $(3 / 6)$, melatonin (2/5), olanzapine $(2 / 2), \quad 5$ hydroxytryptophan $(1 / 2)$, amitriptyline and mirtazapine $(1 / 1)$ and $\mathrm{KD}$, the latter was effective in one patient but

Table 5

Genotype-phenotype correlations in Alternating Hemiplegia of Childhood.

\begin{tabular}{|c|c|c|c|c|c|c|c|c|c|c|}
\hline & $\begin{array}{l}\text { Group 1 } \\
\text { D801N } \\
\text { Mutation } \\
N=8\end{array}$ & $\begin{array}{l}\text { Group } 2 \\
\text { E815K } \\
\text { Mutation } \\
N=7\end{array}$ & $\begin{array}{l}\text { Group } 3 \\
\text { Other Mutation } \\
N=9\end{array}$ & $\begin{array}{l}\text { Group } 4 \\
\text { No } A T P 1 A 3 \\
\text { Mutation } \\
N=4\end{array}$ & $\begin{array}{l}p \text {-Value } \\
1 \text { vs } 2\end{array}$ & $\begin{array}{l}p \text {-Value } \\
1 \text { vs } 3\end{array}$ & $\begin{array}{l}p \text {-Value } \\
1 \text { vs } 4\end{array}$ & $\begin{array}{l}p \text {-Value } \\
2 \text { vs } 3\end{array}$ & $\begin{array}{l}p \text {-Value } \\
2 \text { vs } 4\end{array}$ & $\begin{array}{l}p \text {-Value } \\
3 \text { vs } 4\end{array}$ \\
\hline & $N(\%)$ & $N(\%)$ & $N(\%)$ & $N(\%)$ & & & & & & \\
\hline $\begin{array}{l}\text { Cognitive impairment } \\
\text { Absent/ mild } \\
\text { Moderate/ severe }\end{array}$ & $\begin{array}{l}4(50) \\
4(50)\end{array}$ & $\overline{-}$ & $\begin{array}{l}5(55.6) \\
4(44.4)\end{array}$ & $\begin{array}{l}1(25) \\
3(75)\end{array}$ & 0.07 & 1 & 0.57 & 0.03 & 0.36 & 0.56 \\
\hline $\begin{array}{l}\text { Dystonia } \\
\text { Absent/ mild } \\
\text { Moderate/ severe }\end{array}$ & $\begin{array}{l}8(100) \\
-\end{array}$ & $\begin{array}{l}1(14.3) \\
6(85.7)\end{array}$ & $\begin{array}{l}7(77.8) \\
2(22.2)\end{array}$ & $\begin{array}{l}2(50) \\
2(50)\end{array}$ & 0.001 & 0.47 & 0.09 & 0.04 & 0.49 & 0.53 \\
\hline $\begin{array}{l}\text { Walking } \\
\text { Autonomous } \\
\text { Not autonomous/impossible }\end{array}$ & $\begin{array}{l}8(100) \\
-\end{array}$ & $\begin{array}{l}2(28.6) \\
5(71.4)\end{array}$ & $\begin{array}{l}8(88.9) \\
1(11.1)\end{array}$ & $\begin{array}{l}4(100) \\
-\end{array}$ & 0.007 & 1 & - & 0.03 & 0.06 & 1 \\
\hline $\begin{array}{l}\text { Language impairment } \\
\text { Absent/ mild } \\
\text { Moderate/ severe }\end{array}$ & $\begin{array}{l}8(100) \\
-\end{array}$ & $\overline{7}(100)$ & $\begin{array}{l}4(44.4) \\
5(55.6)\end{array}$ & $\begin{array}{l}2(50) \\
2(50)\end{array}$ & 0.0001 & 0.03 & 0.09 & 0.09 & 0.11 & 1 \\
\hline
\end{tabular}

Bold $=$ statistically significant - Fisher's exact test. 


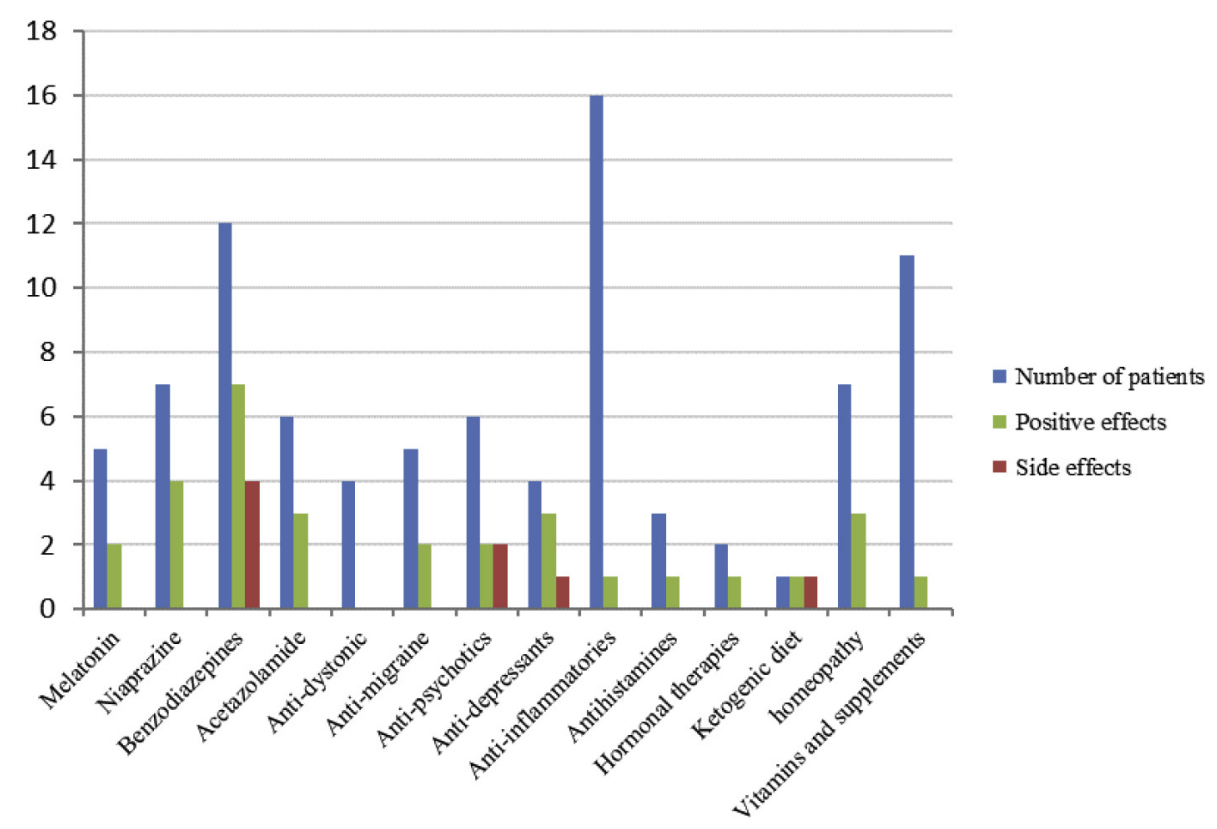

Graph 1. Drugs other than flunarizine used as prophylaxis of paroxysmal attacks in Alternating Hemiplegia of Childhood.

had to be discontinued due to side effects. Many drugs were administered without efficacy on paroxysmal attacks including levodopa-carbidopa (1/30), amantadine $(1 / 30)$, baclofen $(2 / 30)$, and anti-migraine therapies (nimodipine, pizotifene, clonidine, each in 1/30). Risperidone, an anti-psychotic drug, was administered to $2 / 30$ (no efficacy in $2 / 2$ ), and haloperidol was given to $2 / 30$ (clinical worsening in both patients), while among antidepressants, sertraline was given to $1 / 30$ (no effects on attacks) and paroxetine to $1 / 30$ (with side effects) (Graph 1).

Regarding the acute treatment of attacks (Graph 2), benzodiazepines proved helpful in $25 / 27$, niaprazine in $5 / 5$, chloral hydrate in $2 / 2$. The most often used among benzodiazepines was diazepam $(25 / 30)$ which was effective in $19 / 25(76 \%)$ and showed side effects in $6 / 25(24 \%)$ [intense sedation $(n=2)$, paradoxical

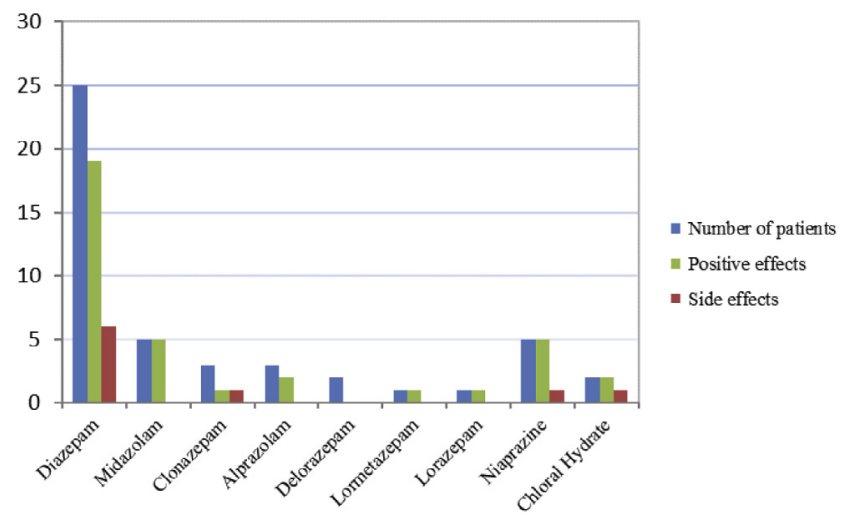

Graph 2. Drugs used in the treatment of acute paroxysmal attacks in Alternating Hemiplegia of Childhood. effect $(n=2)$, hypoventilation $(n=2)]$. Among other drugs, midazolam was used in $5 / 30$ (and was effective in $5 / 5$ patients), clonazepam in $3 / 30$ (effective in $1 / 3$ ), alprazolam in $3 / 30$ (positive effects in $2 / 3$ ), lormetazepam in $1 / 30$ and lorazepam in $1 / 30$ (effective in both patients). Delorazepam was given to $2 / 30$ patients, though without any effect.

\section{Discussion}

No drugs are currently available to cure AHC. Presently, drugs are being used to reduce paroxysmal attacks, to treat epilepsy when present, and to minimize chronic neurological manifestations. Several drugs have been used in the last years to treat paroxysmal symptoms, but flunarizine represents the current drug of choice [4]. Flunarizine is a non selective blocker of voltage-dependent calcium channels and it has recently been demonstrated that it also blocks sodium currents, thus preventing high frequency firing of cortical neurons and decreasing cortical hyperexcitability [5]. Several case reports and case series reported its efficacy in reducing the number of attacks and their duration [2-4] but prospective, randomized, controlled trials are still lacking because of the rarity of this disorder.

In our series, flunarizine proved to be efficacious in $23 / 28(82 \%)$ patients. Side effects were mild and tolerable; none of the patients discontinued the drug solely because of adverse effects but mainly due to a lack of efficacy.

We observed that in younger patients flunarizine was significantly more efficacious in reducing intensity. It is possible that the natural history of AHC, which over 
the years has shown a noteworthy reduction in frequency and intensity of paroxysmal attacks [2], may have biased the true efficacy of flunarizine in the adult patients of our cohort.

Despite positive response in many AHC patients, the role of flunarizine in changing the course of the disease, and especially the cognitive outcome, is still uncertain. The Flunarizine Index, defined as the duration of the treatment with flunarizine divided by the patient's age, was meant to investigate a possible positive or negative correlation between the duration of treatment and the developmental outcome. This could be considered an important index since most patients end up receiving the medication for years [2]. Some authors raised the possibility that flunarizine could have a long-term effect on the motor and intellectual development in responding patients [3], in particular, the same authors recently demonstrated that 8 patients ( 5 of whom were affected by the $\mathrm{E} 815 \mathrm{~K}$ mutation) with severe motor deterioration had not been administered flunarizine during the period of deterioration [6]. Our experience does not support this finding. First of all, in accordance with Mikati and co-authors [2], we did not observe a correlation between the developmental outcome and the duration of the treatment with flunarizine, or its efficacy on the duration, intensity and frequency of attacks. Moreover, 3 of the patients in our cohort with the E815K mutation (patients n. 17, 18 and 26) presented rapid motor deterioration, a sudden worsening of dystonia and loss of language despite ongoing treatment. As far as psychomotor deterioration is concerned, we suspect that a genetic factor rather than the treatment with flunarizine could be primarily involved, since it is now known that patients with E815K have one of the most severe phenotypes [7]. Interestingly, this kind of clinical course showing severe deterioration and no recovery is typical of Rapid Onset Dystonia Parkinsonism, another allelic disorder caused by the ATP1A3 mutation [6]. On the other hand, it seems that long term motor outcome of our ATP1A3 genetically confirmed patients is better than in previous studies: $17 / 26$ patients $(65.4 \%)$ could autonomously walk versus $14 / 33-42.4 \%$ of the Japanese cohort [6]; $6 / 26$ patients $(23.1 \%)$ did not present dystonia versus $6 / 45-13.3 \%$ of the Chinese cohort [8]. In both cohorts, proportion of patients continuously treated with flunarizine was lower $[6,8]$. These data, together with the good clinical course seen in at least $30 \%$ of our patients, may prompt a long-term usage of flunarizine in individual clinical situations. Further larger studies are needed to investigate a possible protective role of therapy with flunarizine.

Genotype may also affect response to treatment with flunarizine, but we were unable to find any correlation between the efficacy of flunarizine and genotype. To date, no studies but the present one have specifically analysed this kind of correlation, therefore we can conclude that flunarizine should be administered to all patients, regardless of the type of mutation, however this hypothesis needs to be further investigated in future studies.

Considering the high frequency of epilepsy in this disease (50\% according to the literature) and the difficulty in making a differential diagnosis, patients often try many different AEDs before starting flunarizine and they continue both therapies even after receiving a definitive diagnosis of AHC. This is why it was difficult for us to understand the real efficacy of AEDs on nonepileptic attacks.

Interestingly, in our cohort other prophylactic drugs such as benzodiazepines in $58 \%$, niaprazine in $57 \%$, acetazolamide in $50 \%$, melatonin in $40 \%$ also proved to be effective, as did some other therapies with olanzapine, 5-hydroxytryptophan, amitriptyline and mirtazapine, which had been administered to a few patients. No clear rationale exists towards the prescription of any of these drugs. However, we do know that trigger factors such as stress, tiredness or strong emotions can induce or worsen paroxysmal episodes. We hypothesize that by improving the wake-sleep cycle or reducing anxiety and depression in our patients some of these drugs may have had secondary effects on paroxysmal episodes.

Interestingly, some authors reported that a KD had a beneficial effect on paroxysmal attacks in some AHC patients $[9,10]$. One of our patients (patient n. 27) had an excellent response with a traditional KD; however, KDs are very difficult to manage and after one year the diet was discontinued due to side effects (vomiting, increase in cholesterol and transaminases, weight gain). Taken together, all these observations suggest that a KD might represent a promising therapeutic option in AHC.

Our study underlines that benzodiazepines represented the drug of choice for the acute treatment of hemiplegic attacks in our cohort, leading to resolution or reduction in severity. Other acute treatment options could be niaprazine and chloral hydrate, which however, are not available for use outside the hospital in Italy.

In general, it is very important to recognize and prevent the trigger factors of hemiplegic attacks, such as strong emotions, physical effort, sudden temperature changes and bathing. Many families report that in most cases medical intervention is not needed; merely placing the patient in a quiet environment, sheltered from light and noise, may lead to relaxation and sleep [11].

The main limitation of our study is its retrospective nature. We know that this type of study is subject to some biases. However, given the lack of randomized and controlled studies, and most of all, of a reliable rationale for choosing appropriate drugs, we do believe that our observations might be beneficial to clinicians who need to choose the most suitable treatment strategies to deal with this rare disorder. 


\section{Conclusions}

In our Italian cohort, flunarizine was the most commonly used drug. A significant improvement in terms of reducing duration, intensity and frequency of attacks was observed between pre- versus post-treatment. Genotype does not seem to influence the response to flunarizine; however, larger controlled studies are warranted. Several other drugs might be used to improve patients' health as well as to reduce the intensity and frequency of paroxysmal attacks. Further studies on the response to treatment in a cohort of AHC patients affected by the ATP1A3 mutation, together with the recent discovery of the biological basis of the disorder, will contribute to clarifying the pathophysiology and providing the rationale for the use of newer and more efficacious molecules.

\section{Acknowledgements}

We thank A.I.S.E.A - the Italian Association for Alternating Hemiplegia of Childhood, for its organizational support.

We thank Ms Valerie Frances Perricone for English editing.

We also acknowledge Borgatti R, Cardona F, Cernetti R, Di Rosa G, Gambardella A, Giacanelli M, Incorpora G, Santucci M, Sartori S, for their involvement in collecting and updating their patients' data for the I.B.AHC Biobank and Clinical Registry for AHC.

\section{Appendix A. Supplementary data}

Supplementary data associated with this article can be found, in the online version, at http://dx.doi.org/10. 1016/j.braindev.2017.02.001.

\section{References}

[1] Heinzen EL, Swoboda KJ, Hitomi Y, Gurrieri F, Nicole S, De Vries B, et al. De novo mutations in $A T P 1 A 3$ cause alternating hemiplegia of childhood. Nat Genet 2012;44:1030-4.

[2] Mikati MA, Kramer U, Zupanc ML, Shanahan RJ. Alternating hemiplegia of childhood: clinical manifestations and long-term outcome. Pediatr Neurol 2000;23:134-41.

[3] Sasaki M, Sakuragawa N, Osawa M. Long-term effect of flunarizine on patients with alternating hemiplegia of childhood in Japan. Brain Dev 2001;23:303-5.

[4] Neville BGR, Ninan M. The treatment and management of alternating hemiplegia of childhood. Dev Med Child Neurol 2007;49:777-80.

[5] Ye Q, Yan LY, Xue LJ, Wang Q, Zhou ZK, Xiao H, et al. Flunarizine blocks voltage-gated $\mathrm{Na}(+)$ and $\mathrm{Ca}(2+)$ currents in cultured rat cortical neurons: a possible locus of action in the prevention of migraine. Neurosci Lett 2011;487:394-9.

[6] Sasaki M, Ishii A, Saito Y, Morisada N, Iijima K, Takada S, et al. Genotype-phenotype correlations in alternating hemiplegia of childhood. Neurology 2014;82:482-90.

[7] Panagiotakaki E, De Grandis E, Stagnaro M, Heinzen EL, Fons C, Sisodiya S, et al. Clinical profile of patients with ATP1A3 mutations in alternating hemiplegia of childhood-a study of 155 patients. Orphanet J Rare Dis 2015;10:123.

[8] Yang X, Gao H, Zhang J, Xu X, Liu X, Wu X, et al. ATP1A3 mutations and genotype-phenotype correlation of alternating hemiplegia of childhood in Chinese patients. PLoS One 2014;9: e97274.

[9] Roubergue A, Philibert B, Gautier A, Kuster A, Markowicz K, Billette de Villemeur T, et al. Excellent response to a ketogenic diet in a patient with alternating hemiplegia of childhood. JIMD Rep 2015;15:7-12.

[10] Vila-Pueyo M, Pons R, Raspall-Chaure M, Marcé-Grau A, Carreño O, Sintas C, et al. Clinical and genetic analysis in alternating hemiplegia of childhood: ten new patients from Southern Europe. J Neurol Sci 2014;344:37-42.

[11] Granata T, Vigevano F, A.I.S.E.A. ONLUS. Alternating Hemiplegia: Italian White Book for Understanding and Managing this Rare Disease. Oggiono (LC): La Nostra Famiglia Association; 2007. 